\title{
Viscoelastic behaviour of a polyester resin concrete reinforced with non- metallic bars under bending loads
}

\author{
José T. San-José \\ PhD Industrial Engineer, Assistant Professor, Dept. of Science of Materials, ESI Bilbao-University of \\ Basque Country (UPV/EHU). Alda. Urquijo s/n, 48013 Bilbao, Spain. \\ Labein Foundation, c/Geldo - Parque Tecnológico de Bizkaia, Edificio 700, 48160 Derio (Vizcaya), Spain.
}

\begin{abstract}
Antonio Aguado
PhD Civil Engineer, Professor UPC Universitat Politècnica de Catalunya. Módulo C-1, Despacho 202 B. C/ Jordi Girona Salgado, 1-3. 08034 Barcelona (SPAIN)
\end{abstract}

Juan M. Manso

PhD Civil Engineer, Assistant Professor, Dept. of Concrete Technology, EPS Univ. of Burgos.Calle Villadiego s/n, 09001 Burgos, Spain.E-mail: jmmanso@ubu.es. Corresponding author.

\begin{abstract}
This paper deals with the study of a highly durable polyester polymer concrete reinforced with glass fibre reinforced polymer rebars. The paper describes the properties of this specific concrete, which were tested using different experimental techniques such as porosimetry, scanning electron microscopy and petrography. Likewise, characterisation in a macro-scale was carried out to define the mechanical properties of the material (modulus of elasticity, stress-strain curve, ultimate strength and bond). Based on the latter properties, the paper presents a relatively simple method to estimate the ultimate bearing capacity of beams under bending load. The calculation method has been verified by testing beams and full-scale elements. At the end, and due to the viscoelastic nature of the polymer, several considerations will be made in order identify safety factors dependent on the loads nature: permanent loads (deferred deformations) and live loads.
\end{abstract}

Keywords: bearing, bending, concrete, deferred, deformations, GFRP, polymer

\section{INTRODUCTION}

The polyester polymer concrete (PPC) is a construction material comprising three phases: inorganic (aggregates), organic (thermosetting polyester resin) and inert (air porosity due to fabrication process). Most of its current applications are related to precast, mainly, isostatic elements such as: crossing slabs, façade panels, drainage elements, farm components; and in-situ 
works: overlays, flooring, rehabilitation concrete works and some structural components in civil works such as slabs [1]. PPC is produced by mixing well-graded inorganic aggregates with a resin binder [2]. The most commonly used binder is unsaturated polyester due to its good properties and relatively low cost. Polymer concrete is strong and durable, presenting low permeability, and rapid curing [3]. Most of its current applications are related to precast building elements

PPC properties depend greatly on the formulation; however, in comparison to conventional Portland cement concrete $(\mathrm{CC})$, may generally be characterised by higher strength, much lower water permeability and greater resistance to weather conditions [4]. In addition to the improved strength and durability, it is also easy to place, cures and develops strength rapidly. However, PC currently has some drawbacks compared to $\mathrm{CC}$, which limits its applications, such as: cost, steel protection and viscoelastic nature. Regarding cost (basically the resin cost because filler costs are comparatively negligible), important research activities [5] are being developed to reduce polymer concrete cost, by controlling the material structure to obtain specific material properties in every application.

Concerning the inorganic phase of PC, the grading curves obtained after sieve analysis of different aggregates should be mixed to achieve adequate concrete in terms of mechanical and durability responses. The Fuller criterion is a common standard [6] for the design of a grading curve and, after the aggregate mix, leads to a linear grain-size distribution. A grading curve after DIN 1045 (the so called gap grading curve) leads to a mix design and polymer concrete with higher mechanical properties than possible with a grading curve after Fuller.

Research works carried out on the material and mechanical properties of polymer concrete, have been widely conducted in Japan, U.S.A. and E.U. Previous studies [7] revealed the large dispersion of some PC characterisation values and the difficulty of current formulations for a precise forecast of those property values. This fact also supports the idea of standardization.

On the other hand, $\mathrm{PC}$ does not provide corrosion protection for steel reinforcement like cement concrete due to its high alkalinity as long as the concrete is not carbonated. Steel reinforcement in polymer concrete should be therefore, if cracks can occur and corrosion causing environment prevails, provided with corrosion protection. The use of fibre reinforced polymer (FRP) bars, to replace steel bars in reinforced concrete, has emerged as one of the many techniques put forward to enhance corrosion resistance of reinforced concrete structures [8]. In particular, FRP rebars offer great potential for use in reinforced concrete [9] under conditions where conventional steel reinforced concrete has yielded unacceptable service. In addition, PC has relatively low tensile strength compared to its compressive strength. Therefore, in many applications, it may be necessary to add chopped strand glass fibres [10] or reinforcing steel to the tensile zone of PC to increase its strength capacity, ductility, and toughness

Reinforced concrete is the most commonly utilized material in the construction of structures and facilities, of which steel reinforcing bar (rebar) has a long history owing to its effectiveness and cost efficiency as concrete reinforcement. However, when the structure is exposed to aggressive environment like de-icing salts, industrial chemicals, and combinations of moisture, corrosion occurs, which accelerates the deterioration of the structure and the loss of its performances and serviceability, and finally, leads to tremendous maintenance costs. 
To mitigate such corrosion problem, several methods have been developed such as epoxy coated rebars, galvanization, stainless steel rebars, cathodic protection. But, these methods presented limited success. For example, it is known that the epoxy coated rebar still showed significant corrosion problems. Since the corrosion of steel rebar is a material problem rather than a structural problem, corrosion cannot be solved without changing the material. This is the reason why composite materials (FRPs), have emerged as an alternative material for steel rebar. FRPs exhibit outstanding characteristics such as corrosion resistance, high specific strength, high fatigue resistance, lightweight, magnetic transparency, non-conductivity, and ease of handling and cutting on site. Their use in civil engineering works dates back to the 1950s when GFRP bars were first investigated for structural use. However, it was not until the 1970s that FRP was finally considered for structural engineering applications, and its superior performance over epoxy coated steel.

The durability of the polymer composite bars is a very complex interaction of mechanisms dependent on the matrix, fibres and interface between both [11]. All elements need to be fully compatible and combined in an appropriate, well controlled, manufacturing process. Besides, the combination of both materials: FRP as the reinforcing component and PC, as the concrete matrix, should come in a highly performance construction material with great expectations for structural [12], durability and aesthetic applications. Given the lack of studies in this field, the present research has been focused on the comprehension of PC and FRP bars materials and their integration throughout bonding experiments, likewise worked out by other authors [13].

The Glass FRP (GFRP) type bars have demonstrated better performance in all aspects of tension behaviour and moisture absorption under the different exposure conditions, when using urethane modified vinyl ester coating and reinforced with ceramic fibers as compared to sand coated surface layer [14]. Alkaline solution at $60^{\circ} \mathrm{C}$ caused the most damaging effect on the ultimate tensile strength for both types of GFRP bars and to a lesser extent, the sabkha and acid solutions at $60^{\circ} \mathrm{C}$. However, the thermal variation, UV radiation and out-door exposure conditions showed no or marginal effect on the ultimate strength. The modulus of elasticity was less affected by all the exposure conditions than the tensile strength. The alkaline solution caused the most reduction in the modulus of elasticity. Other exposure conditions showed similar range of reduction in modulus of elasticity.

The moisture absorption capacity increased with the period for all the exposure conditions. The alkaline solution followed by Sabkha and acid solutions, all at $60^{\circ} \mathrm{C}$, resulted in significant increase in the moisture capacity of GFRP bars when comparing to the thermal variation, UV radiation and out-door exposure conditions. However, extremely high temperature may degrade the mechanical properties of GFRP bars and hence the bond performance, showed a reduction of between 80 to $90 \%$ in the bond strength, as the temperature increased from $20^{\circ} \mathrm{C}$ to $250^{\circ} \mathrm{C}$.

Such us is demonstrated by Salah U. Al-Dulaijan [15] the thermal cycling did increase the bond strength of both types of GFRP bars. The increase in bond strength may be attributed to the increase in confinement pressure against the GFRP bars due to shrinkage of dried cement concrete. Quantifiable effect of aggressive exposure conditions on bond behaviour GFRP bars requires long periods due to the extra protection provided by the $\mathrm{CC}$, which limit the direct 
accessibility of the solution species to the polymer layer surface of GFRP bars. However, this effect will not be possible in the uncracked PC, because of its closure porosity, as presented in this paper.

On the other side, dynamic bond behaviour of GFRP embedded in PC is not yet well known. Besides, some experimental works were performed [16], where the fatigue limit could be estimated around $50 \%$ of the Ultimate Static Strength. In previous research works carried out [17] a relevant temperature rise resulting from friction between the concrete and the GFRP rod was not found. Therefore, the bonding fatigue failure is not expected to occur due to resin degradation of the GFRP bar.

When subjected to a constant load, all structural materials, including steel, may fail suddenly after a period of time, a phenomenon known as creep rupture. Creep tests conducted in Germany by Bundelmann \& Rostasy in 1993, indicate that if sustained stresses are limited to less than $60 \%$ of short-term strength, creep rupture does not occur in GFRP rods. For this reason, GFRP rebars are not suitable for use as prestressing tendons. In addition, other environmental factors such as moisture can affect creep rupture performance. Based on ACI 440 design guidelines, sustained stress may not exceed $20 \%$ of minimum ultimate tensile stress.

\section{MATERIAL ASPECTS}

\subsection{PPC}

To produce economical high performance PPC, an optimum amount of polymer binder is used. On the other side, aggregate proportioning is one of the most important decisions for polymer concrete quality. As all sand and gravel suppliers provide different grading curves, PC producers usually develop programmes to calculate these grading curves. PPC has commonly used aggregates from siliceous, ophitic, limestone or basaltic rocks. Optimum polyester resin and filler contents have been defined as per the best mechanical properties. Dosage study and mixing procedure was performed studying the influence of the percentage of resin and fillers on two PC aspects: strengths (compression and bending) and superficial aspect (aesthetic and durability requirements). The PC dosage analyzed in the present work is presented in Table 1.

On the contrary to $\mathrm{CC}$, the organic nature of the PC admixture binder is based on an unsaturated polyester resin formulation. The resin formulation, acting such as binder, comprises three main components: base orthophthalic polyester resin (produced by condensation of a glycol with two dicarboxilic acids, one saturated and the other unsaturated), reactive diluents (styrene, acting such as crossing agent) and a curing agent, adequate for initiation, maintenance and control of the polymeric chain cross-linking. In this research work, the curing system is composed by a promoter (organic salt, octoate of cobalt) and an initiator (acting as catalysts, being the methyl ethyl ketone).

Once the polymer concrete admixture has been poured into the moulds, 2 hours after the specimens are demoulded and cured at room temperature for 3 days. Afterwards, the post curing was done at $80^{\circ} \mathrm{C}$ during $24 \mathrm{~h}$. During the curing period, the polymer chains of the polyester 
formulation are cross-linked among them, due to the promoter action (curing agent). This linking effect is an exothermic process that implies a relative ordering of the polymeric chains. Both phenomena, chain ordering and the exothermic effect, during the polyester resin curing, involve shrinkage of the polymer concrete matrix during the first 5 to 7 hours, related to the curing period. Thus, the polyester resin was mixed with a commercial compensated shrinkage agent.

The dosage of the PPCs analysed in the present paper is presented in Table 1. Both Utype and G-type have been made of polyester resin but with two different thermosetting resin types; namely, isophthalic and orthophthalic. The casting process has produced two different materials, not only from a chemical point of view but also from a different internal structure, such it will be detailed afterwards.

Table 1 - Polyester polymer concrete components dosage.

\begin{tabular}{|l|c|c|}
\hline Components & Type U & Type G \\
\hline \hline Polyester resin content & $12 \%$ & $12.3 \%$ \\
\hline $\mathrm{TiO}_{2}$ colour additive & $2.5 \%^{(*)}$ & - \\
\hline Carbonate filler & $25 \%$ & - \\
\hline Chalk & - & $7 \%$ \\
\hline Quartz powder & - & $6.7 \%$ \\
\hline Quartz fine sand & $58 \%$ & $24,7 \%$ \\
\hline Quartz sand & $17 \%$ & - \\
\hline Quartz gravel & - & $49.3 \%$ \\
\hline
\end{tabular}

${ }^{(*)}$ With regards to resin content

The microstructure analysis of PPC was obtained through two techniques: $\mathrm{Hg}$ porosimetry and SEM-EDAX analysis. Intrusion porosimetry is a commonly extended analysis technique in the petrography and concrete durability field. This experimental technique was applied on representative irregular samples, previously kiln dried at $60^{\circ} \mathrm{C}$ until constant weight. The sample preparation was performed by covering with a gold layer under vacuum conditions of $3 \cdot 10^{-2}$ mbar during a covering time of $1 \mathrm{~min} 50 \mathrm{~s}$ with $15 \mathrm{~mA}$ of sputtering.

Scanning Electronic Microscopic (SEM-EDAX) analysis was achieved using a JEOL JSM-5600 LV scanning apparatus microscope, with an analyser system EDS ISIS 300 Oxford instrument. Before placing under the microscope, the sample preparation, consisted of covering the sample with gold under vacuum conditions $\left(3 \cdot 10^{-2} \mathrm{mbar}\right)$ during 1 minute and $50 \mathrm{sec}$, and, finally, sputtering at $15 \mathrm{~mA}$. The microscope working conditions were a potential of $20 \mathrm{kV}$ and a working distance of 20 to $25 \mathrm{~mm}$.

Microstructure study reveals that PPC is formed by internal closed pores. This technique was undertaken to observe the interface between aggregates and resin. The internal pore distribution and pore aspect of the analysed polymer concretes can be observed in Figures 1and 2, together with a material detail in Figure 2 (x35) taken by the polarized transmitted light 
microscopy. The internal pore distribution and its area configuration is one of the most important aspects to understand the macroscopic performance of PPC.

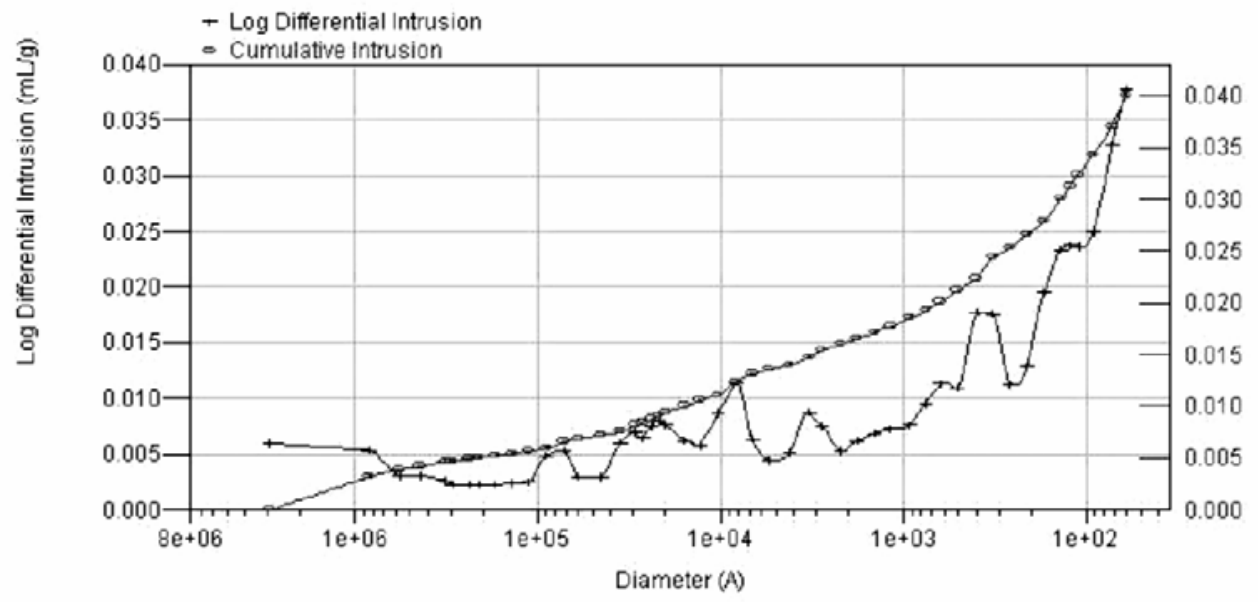

Figure - 1 Porosimetry intrusion and aspect. PPC type U.

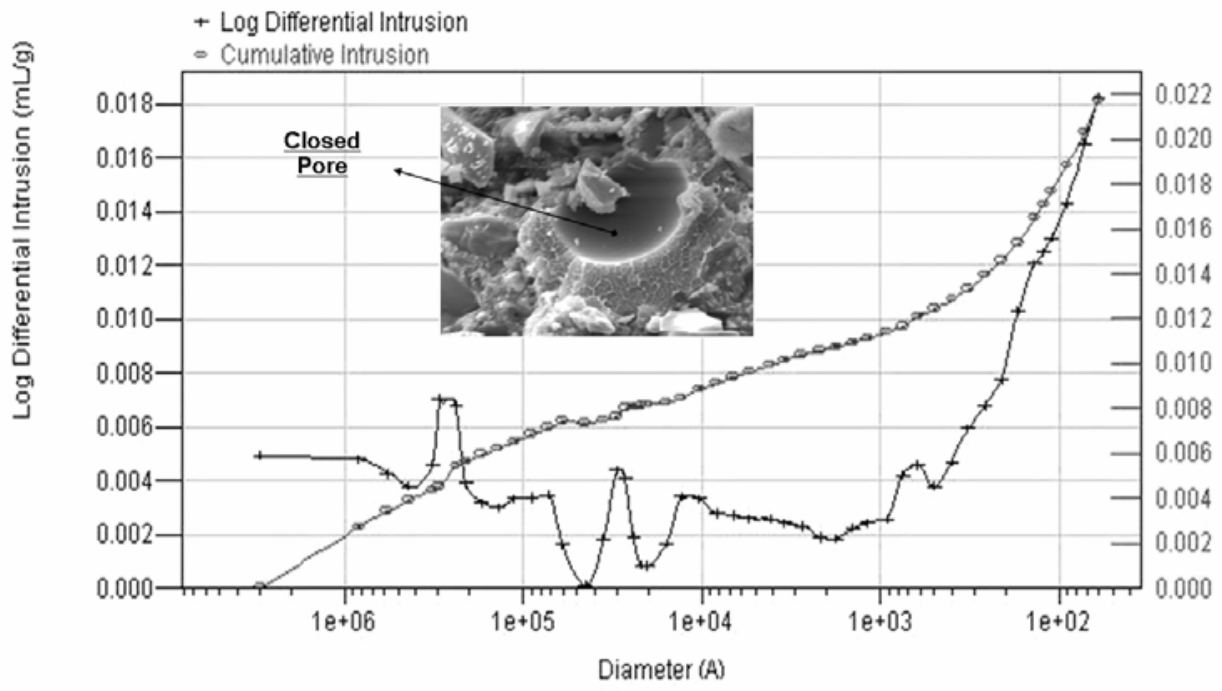

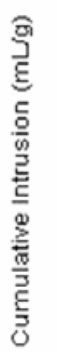

Figure - 2 Porosimetry intrusion and aspect. PPC type G.

Table 2 includes main intrusion porosimetry parameters in both concretes type $U$ and type $\mathrm{G}$, where is presented a good agreement between pores content and bulk density: the higher pores content the less bulk density values.

Table 2 - Polyester polymer concrete intrusion porosimetry results.

\begin{tabular}{|c|c|c|}
\hline PPC types & U-isophthalic & G-orthophthalic \\
\hline \hline Pores Content $(\%)$ & 7.3 & 4.8 \\
\hline Bulk Density $\left(\mathrm{kg} / \mathrm{dm}^{3}\right)$ & 2.32 & 2.39 \\
\hline
\end{tabular}


The SEM-EDAX analysis is presented in Figure 3, showing a thinner resin layer (aggregate wrapping) in the PPC type U. On the other side, the most irregular shapes of the aggregates of the PPC type $\mathrm{G}$ and their higher size improve their anchorage effect in the resin matrix with regard to type U. It can be said, therefore, that type $\mathrm{G}$ is, from a microscopic point of view, a more compact material than type U. It must be also noted that there was a significant difference in size of the air voids in the two PPCs, as it was observed through the porosimetry technique. The different pores distribution can be attributed jointly to the material (dosage ratios) and technology aspects (different casting methods, mixer machines and post-curing conditions).
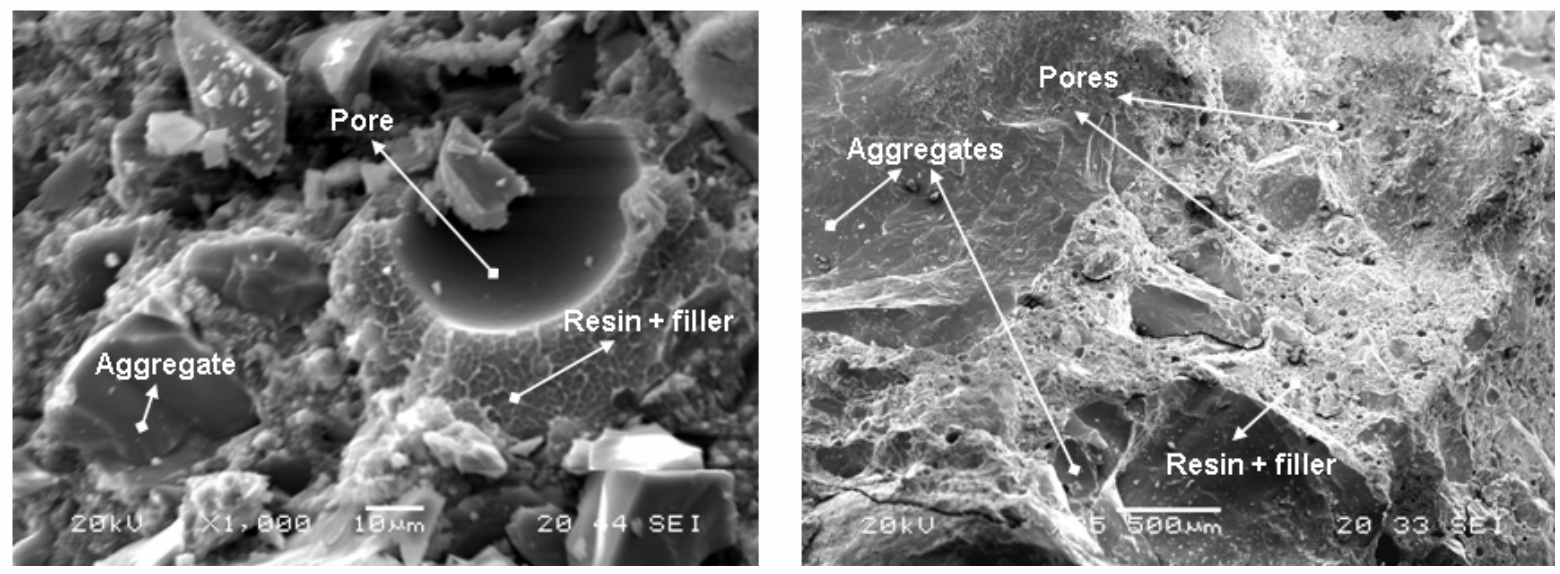

Figure 3 - SEM microphotograph (x35) of PPC type U (left) and PPC type G (right).

Due to the closed microstructure presented in PPC, this is an attractive material to obtain high durability structures. This microstructure continuity, in addition to the organic nature of the binder, facilitates the PC element protection against atmospheric conditions, corrosion and chemical attacks. The PC analyzed corresponds to a structural purposes concrete. Compared with ordinary concrete or commonly aesthetic/architectural PPC purposes, the orthophthalic PPC, presents a compacted interface (the resin layer enveloping the aggregates is greater). In other words, this PPC should present a high continuity to transfer the loads, and consequently, show improved mechanical behaviour, as detailed in the following chapters.

\subsection{GFRP Bars}

FPR bars are formed by long fibres in a thermosetting resin matrix. Therefore, it could be classified as a composite material formed into a long, slender structural shape, suitable for internal concrete reinforcement. Consisting primarily of longitudinal unidirectional fibres bound and shaped by a rigid polymer resin material. The bar may have a cross section of variable shapes (usually circular or rectangular) and a deformed or roughened surface, to enhance bonding mechanisms with concrete. FRP bar suffer a continuous process for manufacturing called "pultrusion" consisting of pulling a fibre-reinforcing material through a resin impregnation bath then a shaping die where the resin is subsequently cured. When processed into a solid form, the resulting composite is characterized good strength and stiffness to weight ratios, excellent chemical resistance and good insulating properties. 
Reinforcing steel and fibre composites exhibit different material behaviors. While reinforcing steel shows ideal elastic-plastic behaviour, all FRP systems are linear-elastic materials. This circumstance must be taken into account in design and dimensioning. The basic fibres of FRP systems are imbedded in a polymer matrix and their arrangement can be unidirectional in the case of reinforcing bars for concrete. Another characteristic is its lightweight and easiness to work with on site having a typical density of $2.2 \mathrm{~g} / \mathrm{cm}^{3}$. Selective appropriate specification of the material, together with long-term savings in repair and maintenance costs, offset the higher material cost (non-metallic rebars are over 10 times the cost of conventional steel reinforcement on a per $\mathrm{kg}$ basis).

The stress-strain relationship in FRP bars is linear-elastic to failure with no significant plastic deformation, prior to ultimate brittle failure, as presented in Figure 4, representing the average curve of 6 tests. In this figure it is shown in detail the longitudinal and transversal sections by using polarized reflected light. The fibres carry the loads and the matrix protects the fibres from mechanical and environmental damage, whilst facilitating load transfer between the fibres through shear mechanisms. From producer data sheets, the glass FRP used in this paper exhibited an ultimate flexural strength of $834 \mathrm{MPa}$ and an interlaminar shear strength of $45 \mathrm{MPa}$. Besides, a typical tensile strength exceeds $1 \mathrm{GPa}$.

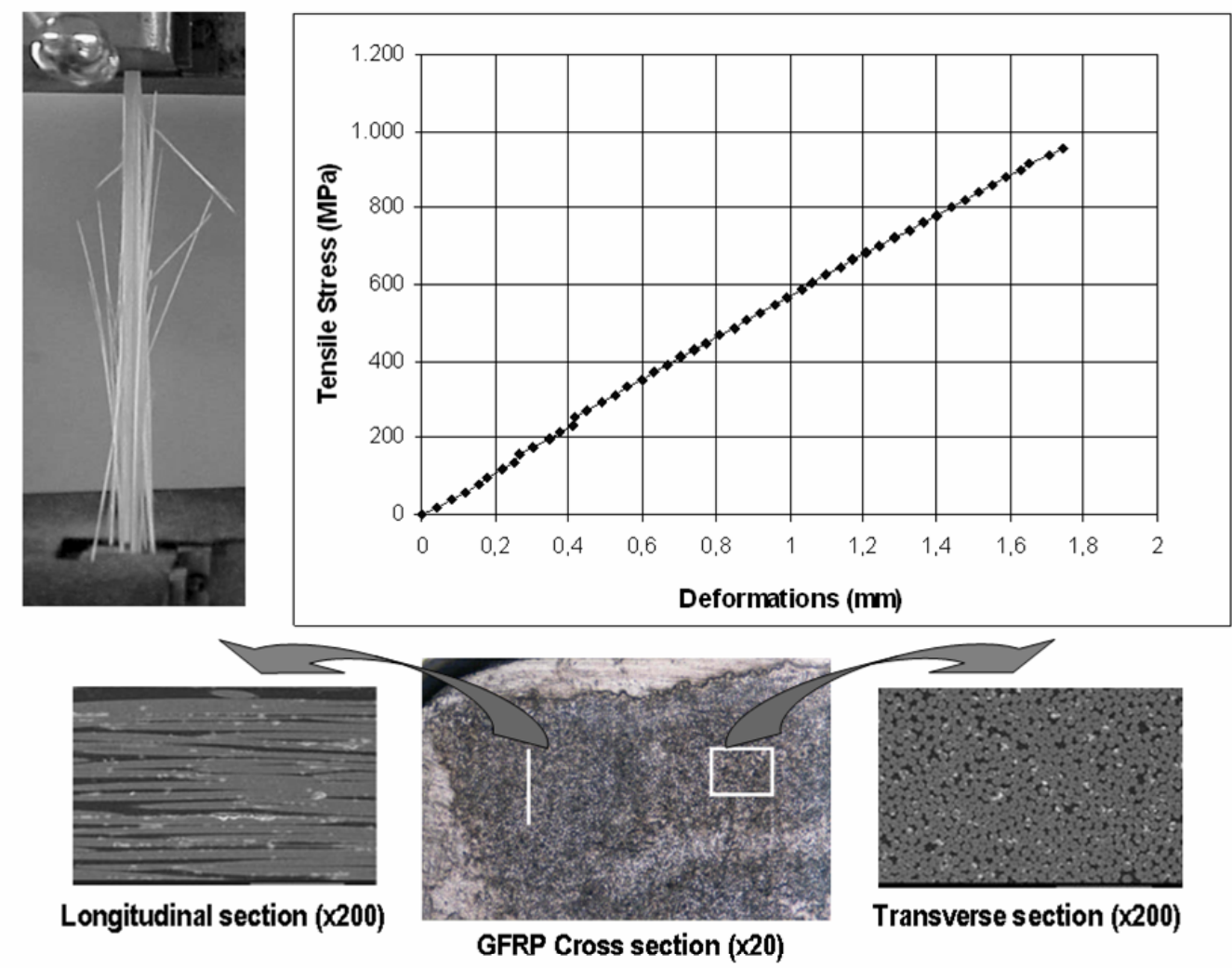

Figure 4 - GFRP bar brittle failure (left), tension tests (right-upper) and section details.

FRP bars have high strength to weight ratios and are suited to strength critical applications. Load is transferred onto non-metallic rebars via a shear-lag process from the 
surface. This results in the bar surface being more highly stressed than the core. As a result, in large diameter bars, core materials may not see any stress.

Two types of reinforcing bars were used during this research. Round mild reinforcing steel bars (B-500 S, as defined in the Spanish Code EHE of $550 \mathrm{MPa}$ ultimate tensile strength, $200 \mathrm{GPa}$ tensile modulus and 22\% failure strength), named in this paper such us "traditional" steel bars, as metallic reinforcement, acting as reference reinforcement bar, and GFRP square bar as non-ferrous reinforcement. The FRP bars use resin systems, fibres and manufacturing processes that underwent extensive testing during four years in the Eurocrete collaborative research programme. They were developed to withstand long-term exposure to the concrete environment and are inherently resistant to chlorides and effects of carbonation. Main properties of the selected bars for this research programme are included in Table 3.

Table 3. Mechanical properties of metallic and GFRP bars

\begin{tabular}{|c|c|c|}
\hline Property & Steel bar & Square GFRP bar \\
\hline \hline Ultimate tensile strength & $550 \mathrm{MPa}$ & $950 \mathrm{MPa}$ \\
\hline Tensile modulus & $200 \mathrm{GPa}$ & $45 \mathrm{GPa}$ \\
\hline Ultimate strain & $22 \%$ & $2,5 \%$ \\
\hline
\end{tabular}

In relation with FRP bars, tensile strength and modulus of elasticity are two of the most important material parameters for designs involving rebar. Unfortunately tensile testing of composites is a notoriously difficult and contentious procedure. This is primarily due to the low shear and transverse properties that result in traditional gripping systems causing damage to the composite. This initiates premature failure in or near to the gripped region thereby invalidating the result. This is exacerbated when testing round rods. Various special end grips have been developed worldwide to accomplish the highest values and there is still no appropriate national or international standard for this test.

Experience has shown that for best results a gauge length of at least $0.5 \mathrm{~m}$ is required to overcome any misalignments in the test set up and any failures that occur closer than $5 \mathrm{~cm}$ to the grips should be discarded. The FRP bar mechanical tests were carried out in accordance with ACI 440.3R-04. The test methods for obtaining the tensile strength, modulus of elasticity and ultimate strain are intended for use in laboratory tests in which the principal variable is the size or type of FRP bar.

In addition, the possibilities for relaxing design for durability requirements developed for carbon steel, such as cover and crack widths, will also moderate as built-costs. These composite materials are insulating, non-magnetic and suitable for use near sensitive electronic equipment and overcoming thermal bridging. Furthermore, it can be readily cut using concrete cutting equipment and are appropriate where concrete requires cutting through. FRP reinforcement has a thermal expansion coefficient, which is $6 \cdot 10^{-6}{ }^{\circ} \mathrm{C}^{-1}$ in the axial direction and around $15 \cdot 10^{-5}{ }^{\circ} \mathrm{C}^{-1}$ in the transverse direction. Different internal stresses will be established within concrete depending on whether cement or polymer based. 
Today, a hybrid Vinylester resin has been identified as being worthy of further study. Thermoplastics with higher shear stress similar to polyesters are being developed and should be reassessed when available. Polyester resins are considered unsuitable for cement concrete where long-term mechanical stress is a design requirement. Polypropylene based matrices are unable to provide sufficient bond strength. Therefore, for orthophthalic polyester concrete, a Bisphenol A unsaturated Polyester resin is selected as the best choice for FRP bars. On the other hand, for cement concrete, a Vinylester resin is proposed as the best available current technology.

The other component of FRP bars, the fibres, has been screened to select the most appropriate for concrete application. From the beginning of the work, four types of fibre reinforcement were targeted as being of potential interest: E glass, AR glass, aramid and carbon. The first, E glass is the most widely used reinforcement in composites. The alkali resistant (AR) glass was developed for resistance to alkaline environments such as cement and concrete. The aramid fibres, available in Europe as Kevlar from DuPont and Twaron from Akzo, also known to be resistant to alkaline environments but sensitive to moisture swelling. Finally, in carbon fibre types there is a wide variety of aerospace grades but recent developments have resulted in the availability of lower cost commercial fibres in Europe. Carbon is inert to most chemicals at the anticipated service temperature of the concrete structures considered.

E-glass fibre ( $70 \%$ by volume) compatible with the above selected resins (PC and FRP binders) has been identified as the most suitable reinforcement for both concrete types, bearing in mind the encapsulation effect of the resin component. It should be noted that many combinations of resins and fibres would work effectively in the given environments. However, each combination should be treated as a unique system. The GFRP used bars in this research have their surface treated with a sand coated layer composed by a well graded quartz $(>98 \%)$ sand of rounded shapes, applied prior to thermosetting of the polymeric resin and with a regular roughness, in order to enhance the adhesion with concrete. Furthermore, a square FRP bar profile is preferred since it provides a greater bond surface area/volume ratio, is easier to assemble in grid form likewise easier and more reproducible during mechanical property testing.

\section{PPC MECHANICAL BEHAVIOUR}

At present, in PPC there are no defined strength classes and there are considerable variations among using different resin types (isophthalic polyester, orthophthalic polyester, hybrid urethane-vinylester, epoxy, acrylic, etc.) and aggregates (types and grades). Mechanical characterization results are presented in Table 4. The mechanical tests, applied on PC, were focused on compression ( 3 specimens of $\varnothing 100 \times 200 \mathrm{~mm}$ size) and flexural ( 3 specimens of $40 \times 40 \times 160 \mathrm{~mm}$ size) behaviour. Tests were carried out as per the specifications established under Rilem TC 113-CPT.

Table 4 includes the fundamental stress-strain parameters obtained under compression and flexural loads. Both PPCs exhibit tensile strengths roughly $25 \%$ the compressive strength, whereas ordinary Portland cement concrete (CC) develops a maximum of $10 \%$ (2 to $7 \mathrm{MPa}$ ). PPC compressive strength can vary over a wide range of values, depending on resin content (not this paper case study) and type of aggregate used (as in this work). 
Table 4. Compression and flexural mechanical PPCs properties

\begin{tabular}{|c|c|c|}
\hline Properties & Type U & Type G \\
\hline \hline Compression strength & $92.0 \mathrm{MPa}$ & $102 \mathrm{MPa}$ \\
\hline Compression modulus (E) & $24,863 \mathrm{MPa}$ & $30,492 \mathrm{MPa}$ \\
\hline Compression max. Strain & $6.5 \%$ & $5.0 \%$ \\
\hline Poisson's ratio & 0.23 & 0.21 \\
\hline Flexural strength & $21.5 \mathrm{MPa}$ & $26.0 \mathrm{MPa}$ \\
\hline Flexural modulus E & $28,710 \mathrm{MPa}$ & $37,868 \mathrm{MPa}$ \\
\hline Flexural max. Strain & $1.0 \% / 00$ & $0.98 \%$ \\
\hline
\end{tabular}

A comparison between both PPCs concludes that differences in flexural properties (strengths and Young modulus) are higher than those ones in compression. The tendency for deformability is the contrary. Therefore, it could be stated that flexural tests are better-suited procedures for ranking and characterizing, mechanically different PC types. However, extensive research should be conducted in future works on polymer concrete and its mechanical properties.

The most effective analysis of both PPC types in compression, can be observed in their respectively stress vs strain curves (Figure 5, curves shape polynomial $2^{\text {nd }}$ degree). As it can be shown, there are some differences, under compression loads, in the type $U$ and $G$ polymer concretes tackled in the present work. Stress-strain curve was plotted by using the data through out the compressive test.
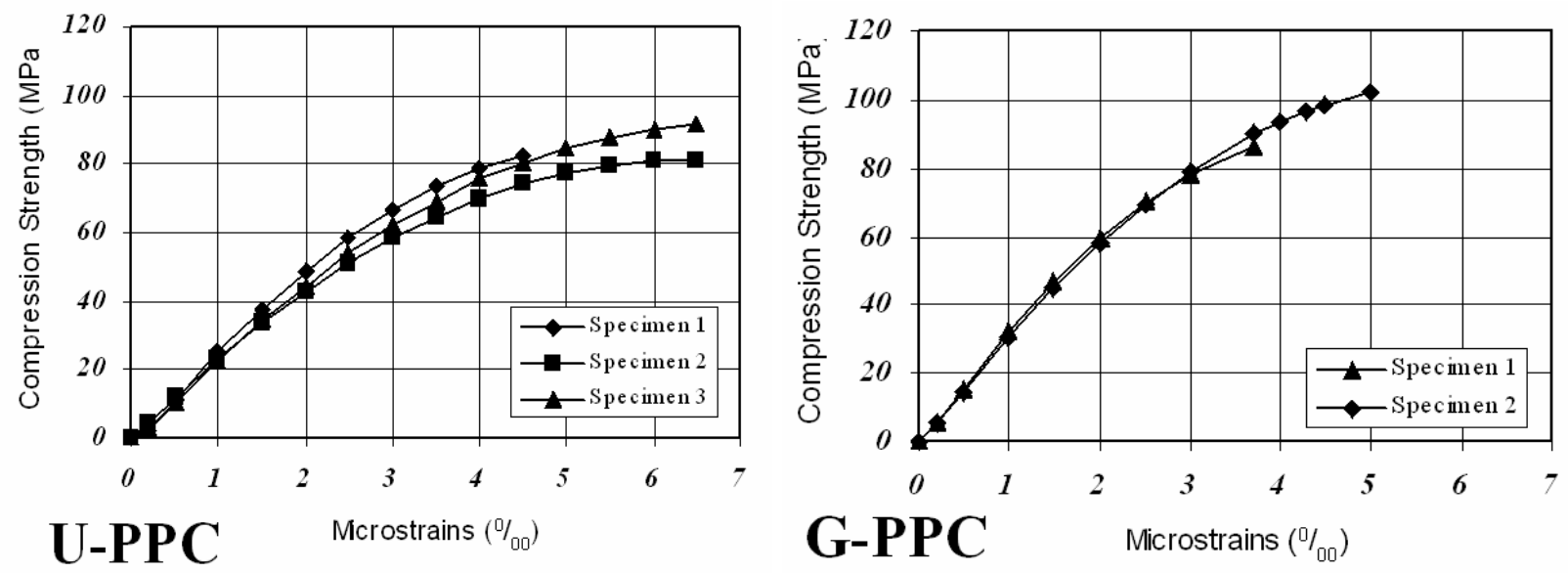

Figure 5 - Compression stress vs strain curves of PPC type U and type G.

Stress-strain curve was plotted by using the data through out the compressive test applied over three specific $\varnothing 100 \times 200 \mathrm{~mm}$ specimens. Besides, the Modulus of elasticity was measured by the strain gauge method, which is one of two methods stipulated in the Rilem method TC 113-CPT (PC-8). Three cylindrical specimens $(\varnothing 100 \times 200 \mathrm{~mm})$ were used in these tests. For measuring the static longitudinal and transversal strain of the specimens, wires of the 
strain measuring apparatus were attached to two diametrically opposite gages, which were positioned parallel to the axis and centered about mid-height of the specimen. During the test, the longitudinal strains, such as the compressive strains, were measured at appropriate load intervals. The transversal strains were used for calculating the Poisson's ratio. Both, the modulus of elasticity and Poisson's ratio, are applicable within the customary elastic working stress range (0$40 \%$ of ultimate concrete strength).

Like CC, PPC has relatively low tensile strength compared to its compressive strength. Therefore, in many applications, it may be necessary to add reinforcing bars to the tensile zone of PPC to increase its strength capacity, its ductility, and its toughness. In order to get the flexural stress-strain curves (Figure 6), it was conducted several tests (prismatic specimens of $40 \times 40 \times 160 \mathrm{~mm}$ ). With regard to measure the deformation of the specimens, a strain gauge were positioned at mid-span, at the lower fiber.
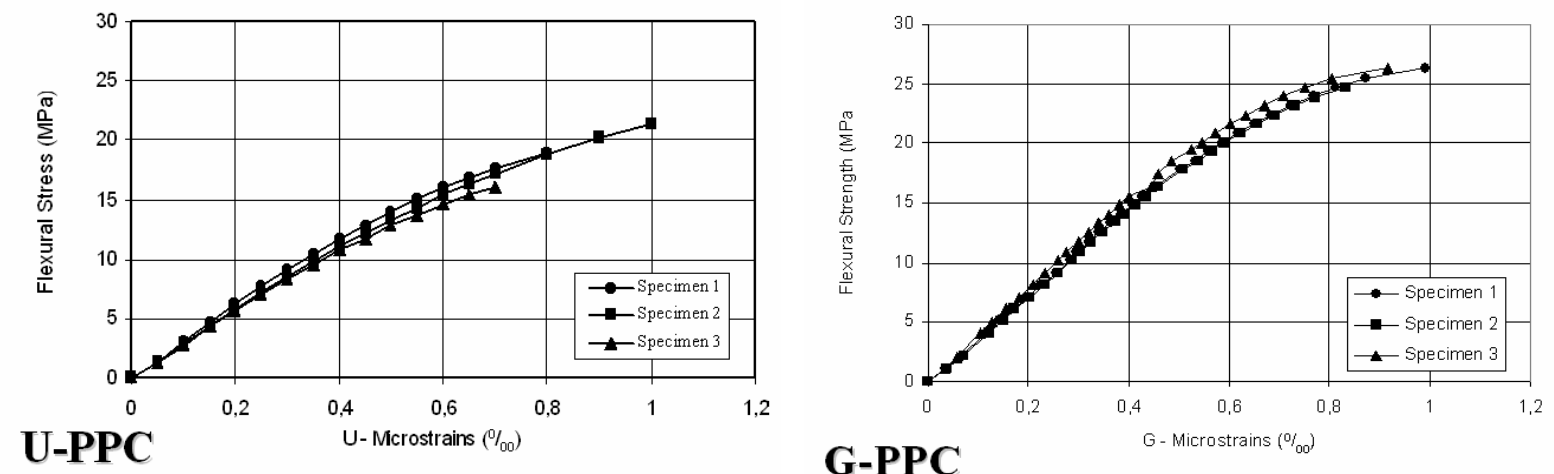

Figure 6 - flexural stress vs strain curves of PPC type U (upper) and type G (down).

The flexural tension strength value obtained in $\mathrm{CC}$ was very small comparing with the PPC one. Nevertheless, when designed by applying the method of ultimate strength design in PPC beams under flexural loads, the equivalent stress block is used only over the neutral axis, that contents the flexural compression part of the cross section, accordingly to the stress distribution of polymer reinforced concrete [18] subjected to flexural loads and affected by the required factors, as presented in last chapter.

The manufacturing process of PPC elements requires well-equipped plants to achieve continuous manufacturing, thus benefiting from a short curing period. PPC can achieve its representative compressive strength properties within 24 hours, although it may take up to 16 days to obtain full cure. In cement concrete this process takes 28 days to achieve a representative strength and may continue to increase in strength over several months.

Because of the organic nature of the PPC binder (thermosetting resin) the thermal conditions applied to the concrete element is a key aspect from a mechanical point of view [19]. This thermal study has been carried out over 21 specimens of $\varnothing 100 \times 200 \mathrm{~mm}$ and other 21 ones of $40 \times 40 \times 160 \mathrm{~mm}$, tested under compression and bending loads, respectively, at different temperatures. 3 specimens per batch will be tested at compression and flexural loads (Rilem TC 
113-CPT), after being exposed, in a climatic chamber, during $3 \mathrm{~h}$ (temperature specimen homogenization), at $40,60,80,120,140$ and $160{ }^{\circ} \mathrm{C}$, respectively. The results appear in Figure 7.

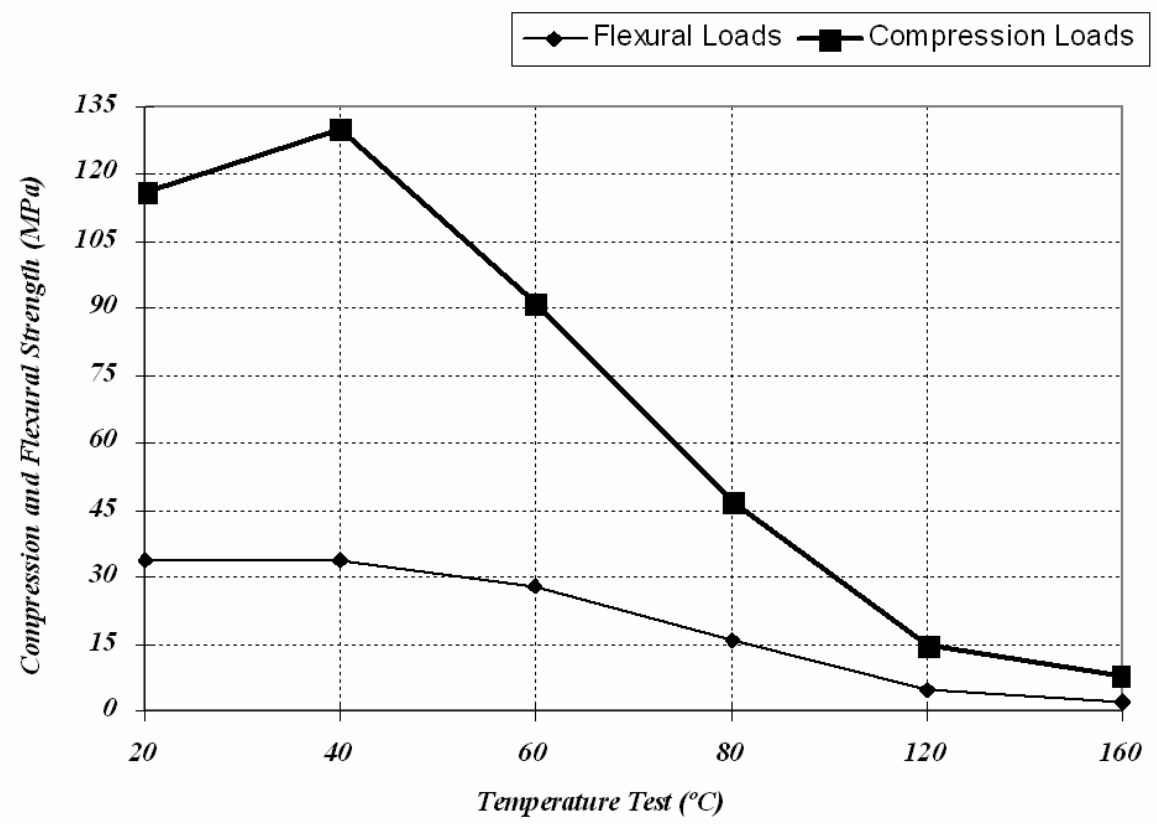

Figure 7 - Temperature influence on compression and flexural strength of PPC type G.

The simultaneity of mechanical and thermal actions up to $60^{\circ} \mathrm{C}$ (regular peak for strongly exposed sunny areas) implies a reduction of more than $10 \%$ in strength. Therefore, any partial safety factor because of thermal exposition conditions should be assigned in PPC structural components.

Because of the viscoelastic nature of the PPC binder, in addition to the thermal effect, the time dependent nature of the loads should be analyzed. At this respect, if the applied loads are maintained for a long time, the creep effect should be considered. This is a useful analysis in real structures, where the loads are divided among dead/permanent loads (own-weight) and live loads. Such us is presented in Figure 8, following ASTM C 512 2002, the creep behavior has been analyzed by applying three different compression stress levels $(30 \%, 35 \%$ and $40 \%$ of compression strength) at one $\varnothing 100 \times 200 \mathrm{~mm}$ cylindrical specimen per load level of PPC type G. Simultaneously, a reference specimen was used as a control one to avoid the influence of room temperature effect over the adquisition data set. The text has been extended along 2.100 hours.

The obtained curve shapes (strain vs. time) are similar to that obtained from traditional concrete, when the stress level is lower than 50\%: curvilinear shape of horizontal asymptote towards a finite value of deformability in compression. Table 5 is prepared with main deformation types obtained: deferred, instantaneous and total strains. It has been verified that the total strain creep is approximately 2 times the instantaneous one at environmental temperature, for the same stress level. Therefore, in the permanent loads situation, stresses levels comprised in the interval $[30 \div 40 \%]$, of PPC compression strength, it has been obtained a finite value of deformability, for a cuasi-infinite period of time. 

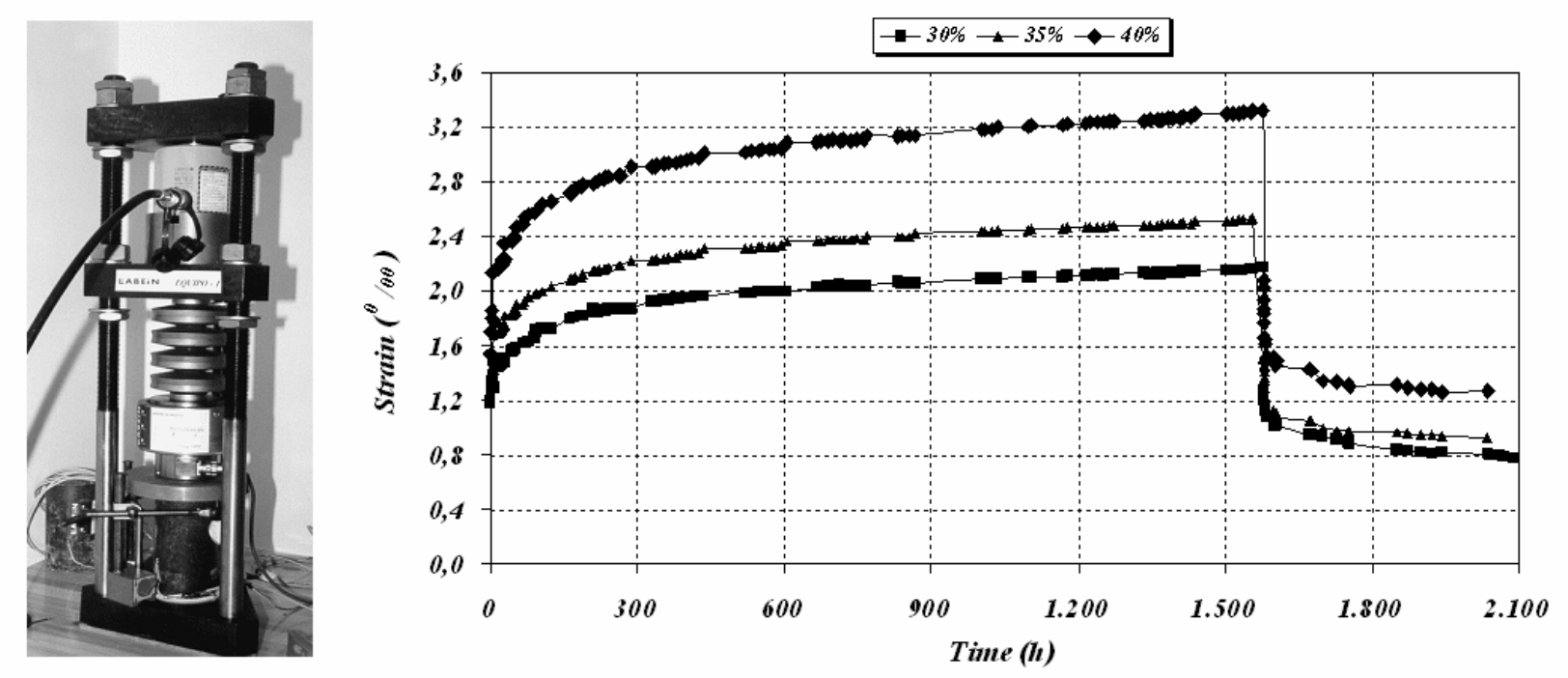

Figure 8 - Creep behaviour of PPC type G under maintained compression loads

Table 5. PPC type G Deformations breakdown under compression creep.

\begin{tabular}{||l|c|c|c||}
\hline \multicolumn{1}{|c|}{ Deformation type } & $30 \%$ & $35 \%$ & \multicolumn{1}{c|}{$40 \%$} \\
\hline \hline Instantaneous $\left(\varepsilon_{\mathrm{EI}}\right)$ & $1.177 \%$ & $1.186 \%$ & $1.541 \% 00$ \\
\hline Total strain $\left(\varepsilon_{\mathrm{F}}+\varepsilon_{\mathrm{EI}}\right)$ & $2.125 \%$ & $2.476 \%$ & $3.243 \% 0$ \\
\hline Deferred strain $\left(\varepsilon_{\mathrm{F}}\right) *$ & $0.948 \% 00$ & $1.29 \%$ & $1.702 \% 00$ \\
\hline
\end{tabular}

$*$ Plastic deferred + Elastic deferred (can be recovered)

Besides, other authors [20] have been proven that for values above $50 \%$ of the compressive strength viscose creep takes place in the PC and therefore, infinite values for the deformability are obtained, compared to $\mathrm{CC}$ which does not exhibit this effect up to values greater than $80 \%$ of its compression strength. On the other side, from the three stress levels considered in present work $(30 \%, 35 \%$ and $40 \%)$, can be obtained the diagrams $\sigma-\varepsilon$ of the PC polyester, under permanent loads, through the creep coefficient $(\Psi)$ :

$\Psi=\varepsilon_{\mathrm{F}} / \varepsilon_{\mathrm{EI}} ; \varepsilon_{\mathrm{T}}=\varepsilon_{\mathrm{F}}+\varepsilon_{\mathrm{EI}}$

where,

$\varepsilon_{\mathrm{F}}=$ Creep Strain and $\varepsilon_{\mathrm{EI}}=$ Elastic instantaneous strain,

where,

$\Psi_{30 \%}=0.81 ; \Psi_{35 \%}=1.09 ; \Psi_{40 \%}=1.10$

On the other hand, there is a relationship between the Young modulus referred to live loads $\left(\mathrm{E}_{\mathrm{CD}}\right)$ and the Young modulus applied to permanent loads $\left(\mathrm{E}_{\mathrm{LD}}\right)$ :

$$
\mathrm{E}_{\mathrm{LD}}=\sigma_{\text {compression }} / \varepsilon_{\mathrm{T}}=\mathrm{E}_{\mathrm{CD}} /(1+\Psi) \quad \mathrm{E}_{\mathrm{LD}}=0.50 \times \mathrm{E}_{\mathrm{CD}}
$$


Taking into account the $\Psi$ average value, it could be established the relationship between the calculus curves for live loads and permanent loads, in the cracking stage of the rectangular cross section under bending loads (only working the upper part over the neutral axis, compression). Therefore, it could be defined appropriate calculus diagrams, such us it will be presented in chapter 5 of present paper.

\section{BOND BEHAVIOUR OF REINFORCING BARS IN PPC}

Because the pull-out test is commonly performed to assess the bond performance of reinforcing bars in concrete. The FRP bar mechanical tests were carried out in accordance with ACI 440.3R-04. The bonding studies were performed by applying the pull-out load via a hydraulic actuator equipped with an MTS load cell of $25 \mathrm{KN}$ maximum capacity and a LVDT, using a MTS controlling unit and a data logger.

The bond mechanism of bars embedded in concrete is the basis phenomenon, which determines the structural behavior of reinforced PPC. Bond of GFRP to concrete is controlled by the following internal mechanisms: chemical bond, friction due to surface roughness of the GFRP rods, mechanical interlock of the GFRP rod against the concrete and a possible hydrostatic pressure against the GFRP rods, due to the shrinkage effect followed along the polymerization process of PPC.

Friction and mechanical interlock are considered to be the primary means of stress transfer. The principal tensile stress caused by bond stresses reach the tensile strength of concrete and micro cracks initiate at the tips of the bar deformations which allow the bar to slip. However, since surface deformations of GFRP bars applied in present paper are "softer" than deformations of steel bars, the initiation of transverse micro cracks are delayed in comparison to steel.

On the other hand, the results in monotonic bonding tests, performed in this research work, were achieved applying the pull-out forces to steel and GFRP bars embedded in an PPC Type G, and CC block cubes of $150 \mathrm{~mm}$. The embedded length was designed in multiples of the bar diameter for steel bars ( $3 \varnothing$ in PPC and $6 \varnothing$ in CC) or side dimensions of the GFRP bar (3L and $6 \mathrm{~L}$, in the same way). The two ends of the bar in the concrete cube were isolated, using plastic bushes, to avoid adherence in those parts of the specimen. The diameter or side of the rods was 8 $\mathrm{mm}$ and the load to the FRP bar was applied at a load rate no greater than $20 \mathrm{kN} / \mathrm{min}$, as recommended in ACI 440-3R.

The reference concrete was a common CC composed of $400 \mathrm{~kg} / \mathrm{m}^{3}$ of cement type IIA-L $42,5 \mathrm{R}$ with a compression average strength of $55,7 \mathrm{MPa}$, a W/C ratio of 0.4 . Table 6 . presents the monotonic bonding results of both rebar types embedded in cement and polymer matrixes, respectively. These results present a conservative bond strength calculation mode since this was determined as mean value of three stress levels corresponding to different slips $(0.01 \mathrm{~mm}, 0.1 \mathrm{~mm}$ and $1 \mathrm{~mm}$ ), such us traditionally done in CC. However, if the anchorage capacity of a structural element had to be adjusted, an approach based on the maximum pull-out load should be undertaken. 
Table 6 - Monotonic bond strength of mild steel and GFRP bars.

\begin{tabular}{|c|c|c|}
\hline Concrete type & Steel bar & GFRP bar \\
\hline \hline PPC type G & $24.4 \mathrm{MPa}$ & $14.0 \mathrm{MPa}$ \\
\hline CC & $12.5 \mathrm{MPa}$ & $9.9 \mathrm{MPa}$ \\
\hline
\end{tabular}

As it is observed in monotonic bonding results, the sand-coated GFRP bars provide values of the bonding strength similar to traditional steel embedded in a CC matrix. On the other hand, in PPC, steel bars allow bonding strengths $74 \%$ greater than GFRP rods and in CC, steel bars allow bonding strengths $26 \%$ greater than GFRP rods. All the aforementioned mechanical improvements will imply a higher number of cracks, but thinner, in reinforced PC under flexural loads, in comparison with traditional reinforced CC.

Unlike steel reinforcing bars or pre-stressing tendons subjected to significant sustained stress for long time periods, creep rupture of GFRP bars may take place below the static tensile strength [8]. Therefore, the creep strength should be evaluated when determining acceptable stress levels in non-metallic bars used as reinforcement or tendons in concrete members to resist sustained loads such as self-weight of a member or other forms of dead loads. Creep rupture strength varies according to the type of FRP bars used. While the stress level applied in monotonic pull-out test (9.9 and $14 \mathrm{MPa}$ ) does not exceed 1,5\% of the GFRP minimum ultimate tensile strength, much lower than the maximum recommended by ACI 440 design guidelines, the creep rupture will not occur in GFRP rods at this sustained stresses levels, obtained at bonding tests.

The elastic-brittle response of GFRP-reinforced concrete, means that a stress concentration created by local straining across a concrete crack cannot be dissipated by plastic yielding of the reinforcement. Although local straining causes attenuation and debonding in a similar way to steel, it is evident that slip of the GFRP bar has to be the dominant mechanism if premature brittle failure of the material is to be prevented. Besides, the performed test series give a qualitative indication of the bond behavior; more research is necessary to obtain results for design purpose.

\section{APPROACH TO GENERAL CALCULUS CURVES IN FLEXURAL REINFORCED PPC}

Results achieved for the material and mechanical properties of polymer concrete have been widely conducted by many researcher groups in Japan, U.S.A. and E.U. Previous studies by [21] have concluded by pointing out the large scatter on the other properties values of PPC of identical $100 \mathrm{MPa}$ compression strength, which also influence the structural behaviour; and the difficulty of the actual formulations for a precise forecast of those property values. This fact also supports the idea of standardization.

Such us it was previously stated, one of the main reasons from above considerations arise from the viscoelastic properties of the polymer, which results in creep and sensitivity to temperature, jointly with the adversely influence of continuous exposure to humidity. With regard to consider the viscoelastic nature of the PPC, the concept of permanent and live loads will 
be managed, besides the temperature influence. In the light of the previously determined material stress-strain curves in PPC (figures 5 and 6, obtained at room temperature) under live loads, different safety factors will be presented regarded to consider the effect of higher temperatures $\left(60^{\circ} \mathrm{C}\right)$ and permanent loads, as occurs in real structures. At this respect, the PPC performance could be simplified to Figure 9.

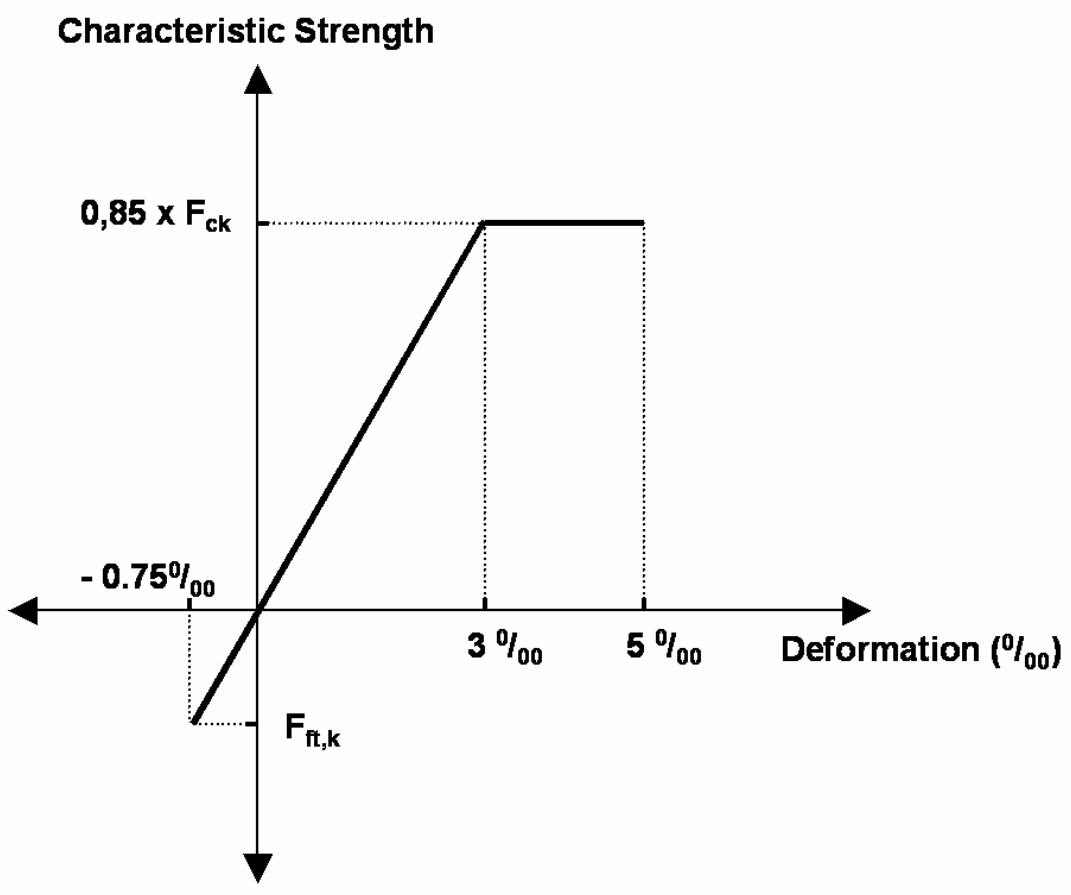

Figure 9 - Stress - Strain simplified diagram in PPC.

Above diagram represents, respectively, the behaviour of the compression (positive strains) and tension stress blocks of a beam cross-section under flexural loads. In the first case, the linear-rectangular shape is a simplification of the Figure 5 polynomial $2^{\text {nd }}$ degree curves, by using the 0,85 factor (nothing to see with the significance of the 0,85 factor in CC) in the rectangular part of the diagram. On the other hand, the tension stress block is a linear curve, as represented in Figure 6. Both cases, the strength limit $\left(\mathrm{F}_{\mathrm{ck}}\right.$ - compression and $\mathrm{F}_{\mathrm{ft}, \mathrm{k}}-$ tension in bending) are the characteristic one that means a 0,95 probability of obtaining higher values, instead the average one adopted initially in Figures 5 and 6. This fact, as traditionally made in $\mathrm{CC}$, permits to calculate the reinforced PPC sections by avoiding different safety factors depending on concrete manufacturing conditions.

From a detailed literature revision ([12], [13], [18], [20] and [21]), several calculation curves have been produced (Figures 10). These calculus diagrams correspond to compression and tension stress blocks based in Figures 5 to 9, by considering the time of applying loads and the temperature conditions of the structure. As it can be observed, the Figure 9 has been divided in two separately figures with regards to present more clearly how the time and temperature effect could affect the PPC structural response. The four presented curves, in each one the following figures, are referred to the live (instantaneous) and permanent loads (that produces deferred deformations) under different temperatures: 
(1) Live (static) loads $22^{\circ} \mathrm{C}$

(2) Live (static) loads $60^{\circ} \mathrm{C}$

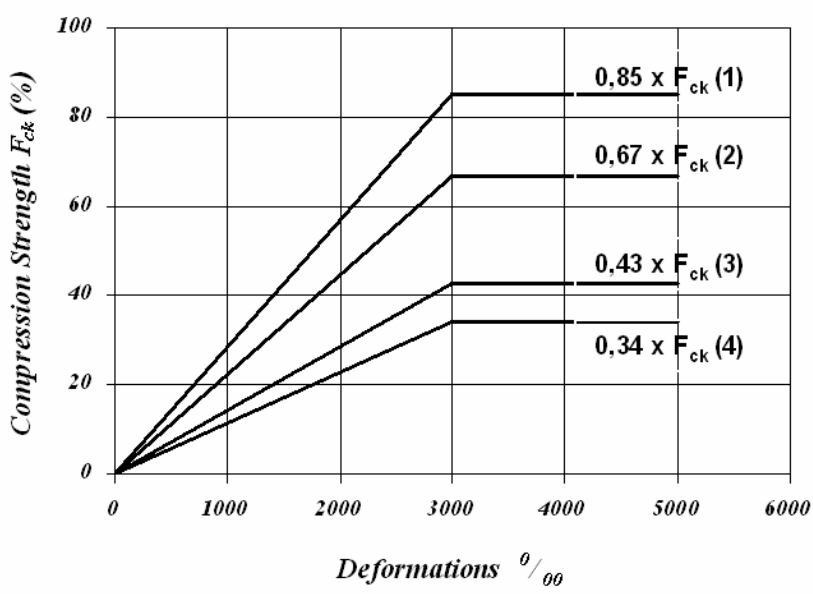

(3) Permanent loads $22{ }^{\circ} \mathrm{C}$

(4) Permanent loads $60^{\circ} \mathrm{C}$

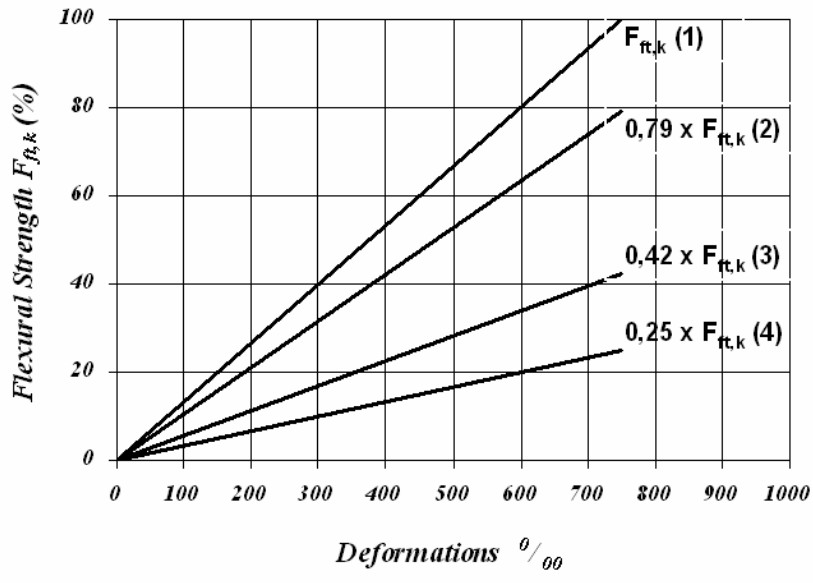

Figure 10 - Flexural - compression (left) and tension (right) calculation diagrams.

A linear combination between the live and permanent loads, joined with the thermal conditions, will be established in relation to the above (1) to (4) curves. Therefore, it will be obtained the PPC stress-strain calculus curve to be applied to the specific reinforced cross section, based on the load hypothesis of the problem.

On the other hand, in order to define the calculus diagrams, as traditionally made in CC, several safety factors have to be defined. Firstly, the loads to be considered, for the thermal ranges analyzed $\left(22^{\circ} \mathrm{C}\right.$ to $\left.60^{\circ} \mathrm{C}\right)$ are: Live loads $(\mathrm{L})$, applied by $\gamma_{\mathrm{L}}$ safety factor and Permanent loads (P), applied by $\gamma_{\mathrm{P}}$ safety factor. In pure flexural, proposes the values [20] of 1.3 and 1.6 for $\gamma_{L}$ and $\gamma_{P}$, respectively. However, these safety factors are different than commonly used for majoring the normal controlled CC. The proportion of the permanent and life loads in the specific hypothesis of the problem will be:

$$
\mathrm{P}[\%]=\frac{100 \cdot \mathrm{P}}{(\mathrm{P}+\mathrm{L})} \quad \text { and } \quad \mathrm{L}[\%]=\frac{100 \cdot \mathrm{L}}{(\mathrm{P}+\mathrm{L})}
$$

The following step, involves the establishment of two parameters: alpha and beta. Both coefficients will depend on the proportions in which the permanent and live load are presented:

$$
\alpha=\frac{\mathrm{P}[\%] \cdot \mathrm{K}_{\mathrm{B}}}{100}+\frac{\mathrm{L}[\%] \cdot \mathrm{K}_{\mathrm{A}}}{100} \quad \text { and } \quad \beta=\frac{\mathrm{P}[\%] \cdot \mathrm{K}_{\mathrm{D}}}{100}+\frac{\mathrm{L}[\%] \cdot \mathrm{K}_{\mathrm{C}}}{100}
$$

Where:

$\alpha$ applies to the compression in bending stress block

$\boldsymbol{\beta}$ applies to the tension in bending stress block 
The above parameters, named as $K_{A}, K_{B}, K_{C}$ and $K_{D}$, are the applied factors to $\mathrm{F}_{\mathrm{ck}}$ and $\mathrm{F}_{\mathrm{ft}, \mathrm{k}}$ in the respective (1) to (4) diagrams, at Figure 7. These K-factors were determined from extensive literature review with the following meanings and values (Table 6):

$\mathrm{K}_{\mathrm{A}}$ : Factor to be applied to $\mathrm{F}_{\mathrm{ck}}$ when bending in compression stress block is produced only by live loads at $22^{\circ} \mathrm{C}$ and $60^{\circ} \mathrm{C}$, respectively, as is shown in curves (1) and (2).

$\mathrm{K}_{\mathrm{B}}$ : Factor to be applied to $\mathrm{F}_{\mathrm{ck}}$ when bending in compression stress block is produced only by permanent loads at $22^{\circ} \mathrm{C}$ and $60^{\circ} \mathrm{C}$, respectively, as is shown in curves (3) and (4).

$\mathrm{K}_{\mathrm{C}}$ : Factor to be applied to $\mathrm{F}_{\mathrm{ck}}$ when bending in tension stress block is produced only by live loads at $22^{\circ} \mathrm{C}$ and $60^{\circ} \mathrm{C}$, respectively, as is shown in curves (1) and (2).

$\mathrm{K}_{\mathrm{D}}$ : Factor to be applied to $\mathrm{F}_{\mathrm{ck}}$ when bending in tension stress block is produced only by permanent loads at $22^{\circ} \mathrm{C}$ and $60^{\circ} \mathrm{C}$, respectively, as is shown in curves (3) and (4).

If other temperatures (comprehended between +22 and $+60^{\circ} \mathrm{C}$ ) should be used for designing conditions, a linear interpolation could be done among the Table 7 respective k-values.

Table 7 - K-factors to be applied to the characteristic PPC strengths in (1) to (4) curves.

\begin{tabular}{|c|c|c|c|c|}
\hline \multirow{2}{*}{ Temperature } & \multicolumn{2}{|c|}{ Compression in bending } & \multicolumn{2}{c|}{ Tension in bending } \\
\cline { 2 - 5 } & $\mathbf{K}_{\mathbf{A} \text { (live loads) }}$ & $\mathbf{K}_{\mathbf{B} \text { (permanent loads) }}$ & $\mathbf{K}_{\mathbf{C} \text { (live loads) }}$ & $\mathbf{K}_{\mathbf{D} \text { (permanent loads) }}$ \\
\hline$+22^{\circ} \mathrm{C}$ & 0.85 & 0.43 & 1.0 & 0.42 \\
\hline$+60^{\circ} \mathrm{C}$ & 0.67 & 0.34 & 0.79 & 0.25 \\
\hline
\end{tabular}

Therefore, as partial conclusion, it could be point out that in the case of only permanent loads at $60{ }^{\circ} \mathrm{C}$, the PPC compression and flexural strengths should be reduced to the $34 \%\left(\mathrm{~K}_{\mathrm{B}}\right)$ and $25 \%\left(\mathrm{~K}_{\mathrm{D}}\right)$ from the initial obtained values in Table 4 . In other words, rectangular sections of reinforced PPC, under a specific combination of live and permanent loads, could be analyzed following the Figure 11:

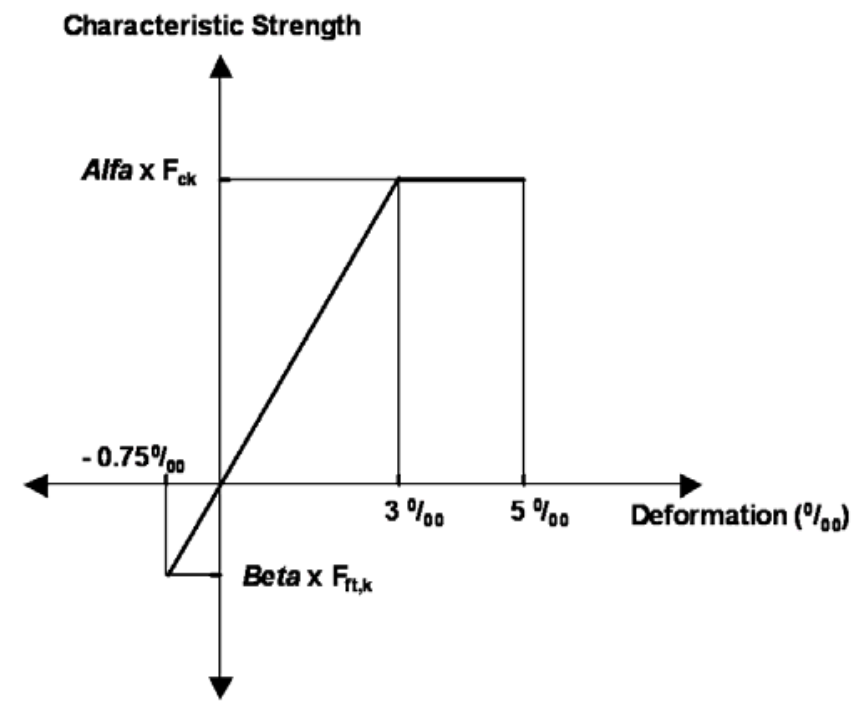

Figure 11 - Calculation diagram for polyester polymer Concrete PPC. 
In the case of rectangular cross sections of reinforced PPC, the equilibrium of loads, jointly with the strains compatibility, Figure 12 , results different internal loads $\left(F_{c}\right.$ plus $\left.F_{a}\right)$ configuration. Due to the maintenance of the planarity of the reinforced PPC cross section, the neutral axis depth " $x$ " covers the following range of values (being "d" the bars depth): $0.333 \cdot d<$ $\mathrm{x}<\mathrm{d}$.

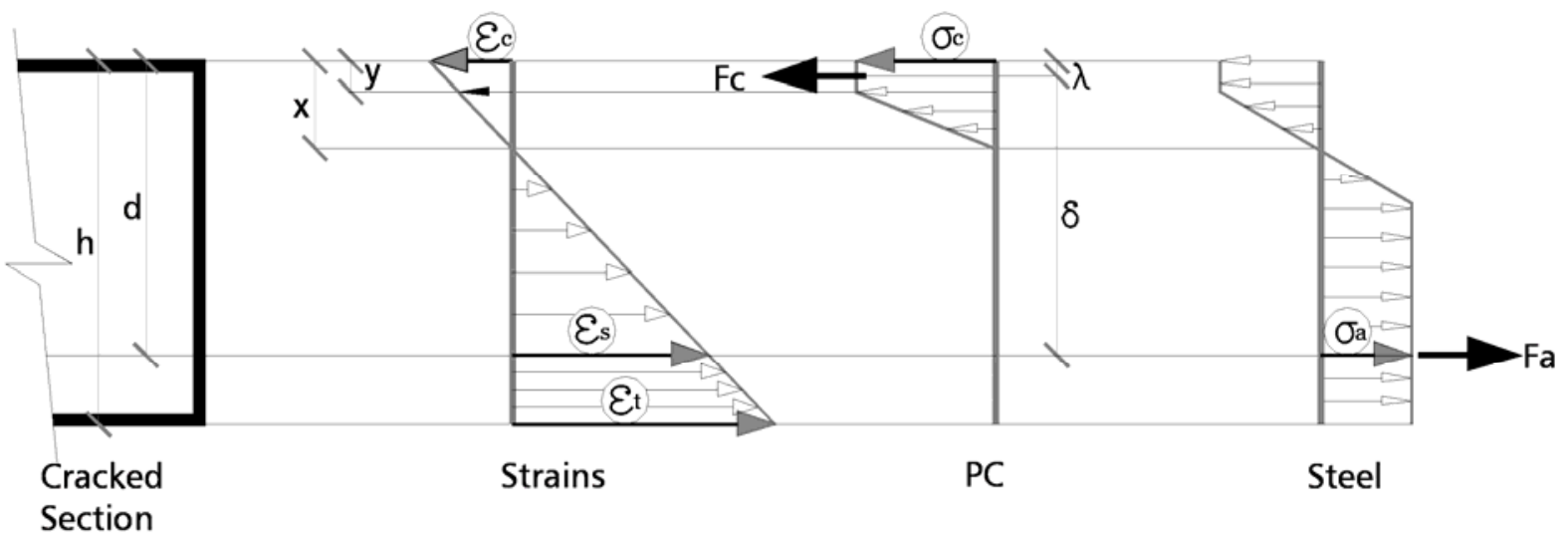

Figure 12 - Cross section loads equilibrium of reinforced PPC under flexural loads.

$$
\begin{aligned}
& 0=F_{c}-F_{a} \quad M_{d}=F_{c} \cdot \delta \quad y=0,4 \cdot x \\
& \mathrm{~F}_{\mathrm{c}}=0,5 \cdot \mathrm{b} \cdot\left(\alpha \cdot \mathrm{F}_{\mathrm{cd}}\right) \cdot(\mathrm{x}+\mathrm{y}) \quad \mathrm{A}_{\mathrm{a}} \cdot \mathrm{f}_{\mathrm{yd}}<\mathrm{F}_{\mathrm{a}}<0,75 \cdot\left(\mathrm{A}_{\mathrm{a}} \cdot \mathrm{f}_{\mathrm{yd}}\right) \\
& \lambda=\frac{\left(x^{2}+y^{2}+x \cdot y\right)}{(3 \cdot[x+y])} \quad \varepsilon_{a}(\% o)=\frac{5 \cdot(d-x)}{x} \\
& F_{c d}=\frac{F_{c k}}{\gamma_{c}} \quad \text { and } \quad f_{y d}=\frac{f_{y k}}{\gamma_{s}}
\end{aligned}
$$

where:

$\mathrm{F}_{\mathrm{ck}} \quad$ is the characteristic compression strength of PPC

$\mathrm{f}_{\mathrm{yk}} \quad$ is the characteristic tension strength of reinforcing bars

$\mathrm{F}_{\mathrm{cd}} \quad$ is the calculus compression strength of PPC

$\mathrm{f}_{\mathrm{yd}} \quad$ is the calculus tension strength of reinforcing bars

$\gamma_{c}$ is the reducing strength safety factor in PPC

$\gamma_{\mathrm{s}} \quad$ is the reducing strength safety factor in the reinforcing bar

Substituting:

$$
\begin{array}{lll}
\lambda=0,371 \cdot \mathrm{x} & \\
\mathrm{F}_{\mathrm{c}}=\mathrm{b} \cdot \mathrm{x} \cdot \mathrm{F}_{\mathrm{cd}} \cdot(0.7 \cdot \alpha) & =\mathrm{b} \cdot \mathrm{x} \cdot \mathrm{F}_{\mathrm{cd}} \cdot(\Psi) \\
\delta \quad=\mathrm{d}-\lambda=\mathrm{d}-(0.371) \cdot \mathrm{x} & =\mathrm{d}-\left(\lambda^{\prime}\right) \cdot \mathrm{x}
\end{array}
$$


$\lambda$ ' and $\Psi$ values are constant in $\mathrm{CC}$ and equal to 0.416 and 0.6681 , respectively. However, in PPC $\Psi$ depends from $\alpha$, linked to: proportion of permanent loads, proportion of live loads and temperature, as referred above.

\subsection{Simplified calculus diagram under live loads}

In order to simplify the calculus method, as traditionally made in $\mathrm{CC}$, the linearrectangular diagram designed before, in compression, could be turned into rectangular stress block. After establishment of the calculation procedures a number of test beams were produced and loaded (100\% live loads) to failure in order to verify the calculations (Figure 13): Beam 0 (two orthophthalic plain PPC beams), Beam 1 (reinforced with $2 \varnothing 8 \mathrm{~mm}$ steel bars) and Beam 2 (reinforced with $3 \varnothing 8 \mathrm{~mm}$ plain GFRP bars). More details are included in Table 8.
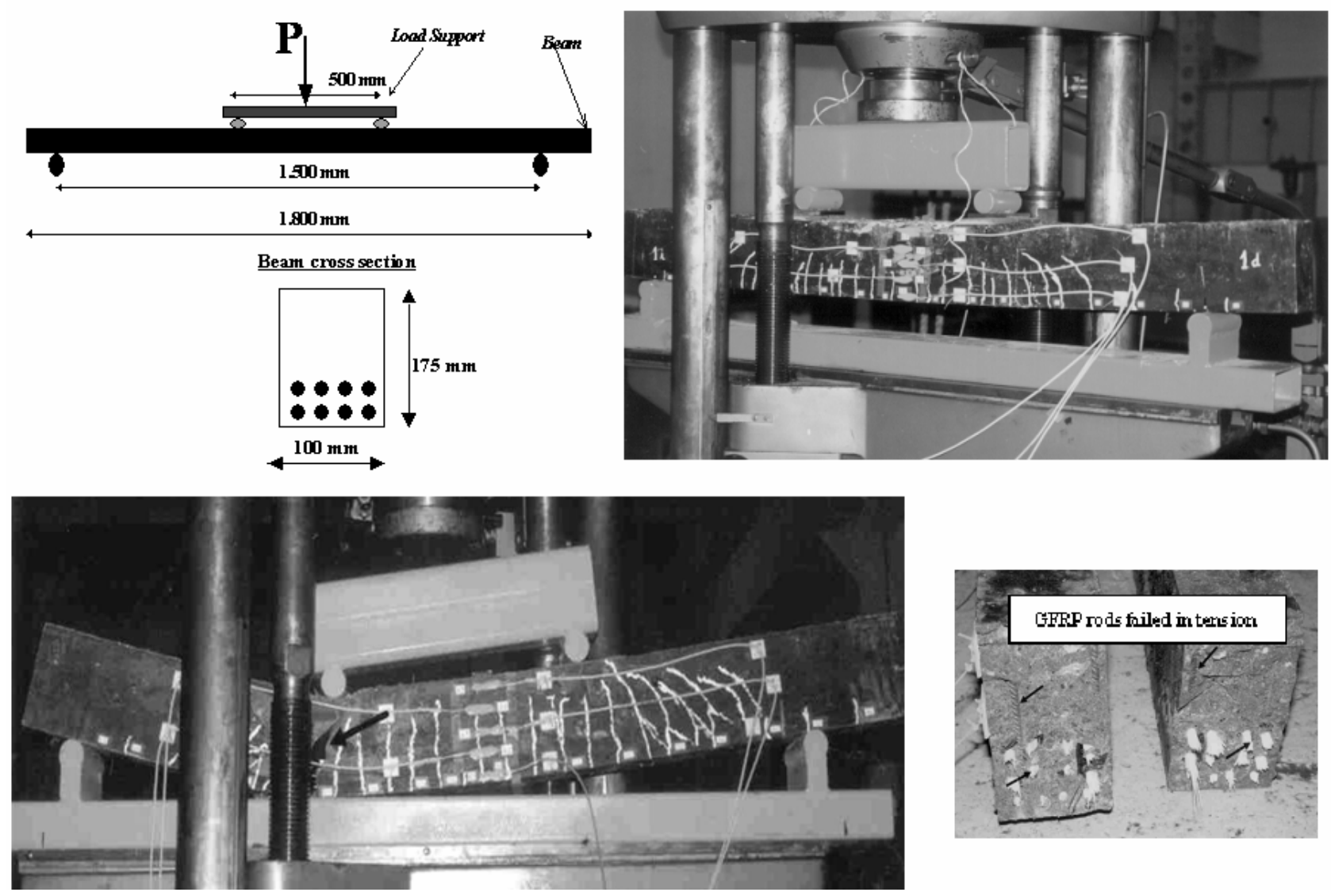

Figure 13 -Beam type 2 previous failure (above) and after bending/shear failure 
Table 8 - Experimental results of bending orthophthalic PPC beams.

\begin{tabular}{|c|c|c|c|c|c|c|c|}
\hline Observed aspects & \multicolumn{2}{|c|}{ BEAM 0} & \multicolumn{2}{|c|}{ BEAM 1} & \multicolumn{3}{|c|}{ BEAM 2} \\
\hline Section (mm) & \multicolumn{2}{|c|}{$100 \times 175$} & \multicolumn{2}{|c|}{$100 \times 175$} & \multicolumn{3}{|c|}{$100 \times 175$} \\
\hline Reinforcement & \multicolumn{2}{|c|}{---} & \multicolumn{2}{|c|}{$10 \varnothing 8$ steel } & \multicolumn{3}{|c|}{12 Ø8 GFRP } \\
\hline $\mathrm{A}_{\mathrm{s}}\left(\mathrm{mm}^{2}\right)$ & \multicolumn{2}{|c|}{0} & \multicolumn{2}{|c|}{502.6} & \multicolumn{3}{|c|}{603.2} \\
\hline Stirrups & \multicolumn{7}{|c|}{$\varnothing 6$ steel $\mathrm{f}_{\mathrm{y}}=510 \mathrm{MPa}, \mathrm{c} / \mathrm{c} 100 \mathrm{~mm}$} \\
\hline Reinforcement degree & \multicolumn{2}{|c|}{ under } & \multicolumn{2}{|c|}{ normal } & \multicolumn{3}{|c|}{ over } \\
\hline Mid span deflection (mm) & 20 & 20 & 103 & 112 & 233 & 215 & 255 \\
\hline Failure load P (kN) & 41.0 & 39.5 & 160.0 & 156.5 & 145.0 & 160.0 & 169.0 \\
\hline Failure moment $(\mathrm{kNm})$ & 10.3 & 9.9 & 40.0 & 39.1 & 36.3 & 40.0 & 42.3 \\
\hline Mode of failure & \multicolumn{2}{|c|}{ bending } & \multicolumn{2}{|c|}{$\begin{array}{l}\text { Concrete crushing } \\
\text { (bending failure) }\end{array}$} & \multicolumn{3}{|c|}{$\begin{array}{c}\text { Concrete rupture } \\
\text { (bending/shear failure) }\end{array}$} \\
\hline
\end{tabular}

Using approaches in Eurocode (EC2-1-1, par 4.2) for traditional reinforced cement concrete, the process of transforming real stress-strain graphs (Figure 5) into rectangular diagrams could, of course, be made in one operation. As the first step in converting the stress-strain diagrams for axial compression, into easily manageable mathematical expressions, the curves were transformed into the best-fitting simple $\mathrm{n}^{\text {th }}$ degree parabolas, having maximum value corresponding to the recorded ultimate strain. The reason to introduce this intermediate step towards a rectangular representation - was to investigate the effect of various degrees of curvature of the graphs.

Considering the shapes of the graphs in Figure 5 it appears - comparing with typical cement concrete graphs - the maximum stress point and maximum strain point are coinciding. This means that up to now the documented degree of plasticity of polymer concrete is restricted. Higher degrees might be determined by more sophisticated procedures and equipment. Introduction of a simple $\mathrm{n}^{\text {th }}$ degree parabola approximation (Figure 14) appeared to be a viable and realistic step further towards the final simplification.

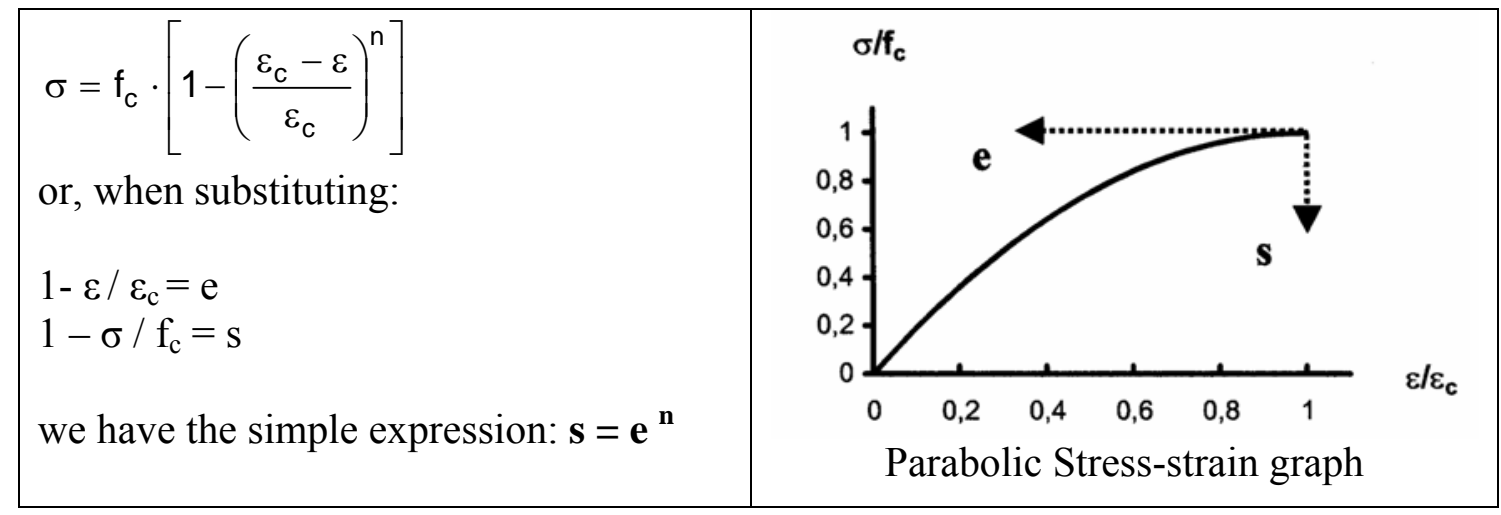

Figure 14 - Parabolic representation of stress-strain graph. 
The curve fitting was defined on basis of minimum deviations between the real stressstrain curve and the $\mathrm{n}^{\underline{\text { th }}}$ degree parabola at a number of points. Parabolas of degree $\mathrm{n}=1.6-2.1$ were very close to the real curves shown in Figure 5. By means of the parabolic expression for the stress-strain relationship it was possible to calculate the following conversion factors $\mathrm{k}_{1}$ and $\mathrm{k}_{2}$, which describe the transformed rectangular stress block shown in Figure 15, ref EC2-1-1 Fig 4.4. The $\mathrm{k}_{1}$ and $\mathrm{k}_{2}$ formulas and values refer to rectangular cross sections of beams, for other section shapes they are different.

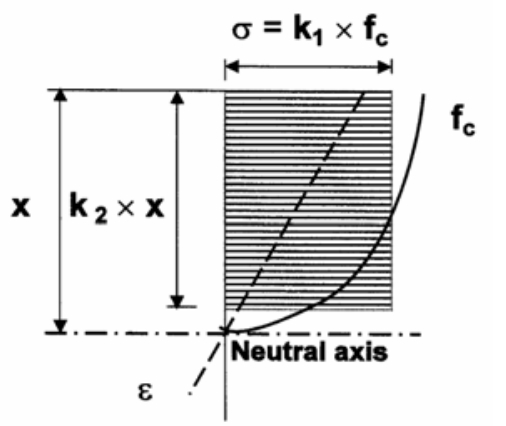

$$
\begin{gathered}
\mathrm{k}_{1}=\frac{\mathrm{n} \cdot(\mathrm{n}+2)}{(\mathrm{n}+1)^{2}} \\
\mathrm{k}_{2}=\frac{\mathrm{n}+1}{\mathrm{n}+2}
\end{gathered}
$$$$
\text { - } \mathrm{n} \text { is the degree of the parabola. }
$$$$
\text { For the graphs }
$$$$
\text { - in Figure } 4 \text { the factors are: }
$$

$$
\begin{array}{ll}
\mathrm{n}=1.6: & \mathrm{k}_{1}=0.85 \quad \mathrm{k}_{2}=0.72 \\
\mathrm{n}=2.1: & \mathrm{k}_{1}=0.89 \quad \mathrm{k}_{2}=0.76
\end{array}
$$

Figure 15 - Factors for converting stress-strain curves into rectangular stress blocks

The ultimate moment capacity at pure flexure for static loads depends i.e. on the percentage of reinforcement, $\rho$. The cross section can be under-reinforced, balanced or overreinforced. As a start the calculation procedures were verified against the obtained failure moment

\begin{tabular}{|c|c|c|c|c|c|c|c|}
\hline Observed aspects & \multicolumn{2}{|c|}{ BEAM 0} & \multicolumn{2}{|c|}{ BEAM 1} & \multicolumn{3}{|c|}{ BEAM 2} \\
\hline Section $(\mathrm{mm})$ & \multicolumn{2}{|c|}{$100 \times 175$} & \multicolumn{2}{|c|}{$100 \times 175$} & \multicolumn{3}{|c|}{$100 \times 175$} \\
\hline Reinforcement & \multicolumn{2}{|c|}{---} & \multicolumn{2}{|c|}{$10 \varnothing 8$ steel } & \multicolumn{3}{|c|}{12 Ø8 GFRP } \\
\hline Reinforcement degree & \multicolumn{2}{|c|}{ under } & \multicolumn{2}{|c|}{ normal } & \multicolumn{3}{|c|}{ over } \\
\hline Measured Failure moment (kNm) & 10.3 & 9.9 & 40.0 & 39.1 & 36.3 & 40.0 & 42.3 \\
\hline Calculated ultimate moment $(\mathrm{kNm})$ & --- & --- & 35.1 & 35.1 & 36.6 & 36.6 & 36.6 \\
\hline Mode of failure & \multicolumn{2}{|c|}{ bending failure } & \multicolumn{2}{|c|}{$\begin{array}{l}\text { Concrete crushing } \\
\text { (bending failure) }\end{array}$} & \multicolumn{3}{|c|}{$\begin{array}{c}\text { GFRP rupture } \\
\text { (bending/shear failure) }\end{array}$} \\
\hline
\end{tabular}
for the full-scale beams referred to in Table 8. The results are shown in Table 9 and it appears that the differences are less than $10 \%$. On average the measured moments are above the calculated.

Table 9 - Measured versus calculated ultimate moment

\section{CONCLUSIONS}

- The casting procedure is one of the most important factors in order to establish the different microscopic and macroscopic behavior of PPC. Porosity, interface aggregates-matrix configuration, strength and deformability, are closely linked. The compression strength of PPC is three times higher than $\mathrm{CC}$ and a minimum bending strength of $25 \mathrm{MPa}$ ). Besides, the differences among the flexural parameters (strengths, strains and E modulus) are higher than in the compression study. Therefore, the flexural test is a better suited procedure for ranking, 
mechanically, the different PPC types in comparison with the compression strength, most adjusted for developing this purpose in the ordinary cement-concrete.

- The sand-coated GFRP reinforced polymer concrete provides values of the bond strength similar to traditional steel bars in reinforced concrete. In polymer concrete, steel bars develop bond strength about $70 \%$ greater than GFRP rods. In cement concrete, steel bars exhibit bonding strength about $25 \%$ greater than GFRP rods.

- The viscoelastic properties of the polymer resin results in creep and sensitivity to temperature. Because of the viscoelastic nature of the PPC, the concept of permanent loads (deferred deformations) and live loads (instantaneous deformations) have been managed, besides the temperature influence, by building several calculus diagrams based in linearrectangular geometries.

- Various safety factors were concluded with regard to consider the effect of temperature $\left(60^{\circ} \mathrm{C}\right)$ and permanent loads. It could be point out that the PPC is extremely sensitive to deferred deformations, being necessary to reduce its high initial strengths to less than a third part, in the case of only permanent loads applied at $60^{\circ} \mathrm{C}$.

- Flexural failure in reinforced PPC beams occurred when the ultimate compressive strain in the concrete reached a value of 0.005 or more. The cracking patterns and the modes of failure of reinforced PPC beams were similar and generally typical to those observed in reinforced Portland cement concrete. However, reinforced PPC beams exhibited higher strength and more ductility than reinforced Portland cement concrete beams. In addition, PPC requires less cover for the tensile reinforcing steel than Portland cement concrete because of its inherent high flexural strength, low permeability, and good chemical resistance.

- The nominal moment strength obtained from these experiments were in good agreement with the theoretical values computed from applying the method of ultimate strength design in the case that the stress distribution of polymer concrete beam, subjected to the flexural moment, was assumed as the equivalent rectangular. However, in order to design the polymer concrete beams more accurately, it is necessary to accumulate much more experimental data from other cross section shapes and other rectangular cross section specimens based on the variation of the compressive strength and the size effect, and the data about the flexural behavior of polymer concrete beams.

\section{REFERENCES}

1. Fowler, DW. Polymers in Concrete - Where have we been and where are we going? Proceeding ICPIC'01. Ed. D. Fowler. Hawai (USA), 2001.

2. A. Avci, A. Academic, H. Arikan. Mixed-more fracture behaviour of glass fibre reinforced polymer concrete. Cem. Concr. Res. 2005; 35:243-247.

3. J. Tomás San-José and Juan M. Manso. "Fibre reinforced polymer bars embedded in a resin concrete: study of both materials and their bond behaviour". Polym. Compos. 2006; $27(3) / 315-322$.

4. R.L. Verleg. Corrosion resistant unsaturated polyester resins; an overview, by DSM-BASF Structural Resins. Proceedings of the Reinforced Plastics Conference, Karlovy Vary (Czech Republic), 1997. p. 90-100.

5. L. Czarnecki, A. Garbacz, P. Lukowski, J. Clifton, Optimization of polymer concrete composites, NISTIR 636, Maryland (USA), 1999. 
6. J. T. San-José y M. Frías, "Hormigón de altas prestaciones basado en aglomerantes poliméricos". Mater. Constr.2007;57(286)/29-39.

7. J. Tomás San-José and A. Aguado, Influence of the viscoelastic nature of the polymer concrete in its structural behaviour. Proceedings International Symposium Polymers in Concrete. ISPIC. University of Minho. pp. 1-15. ISBN 972-99179-1-4. Guimaraes (Portugal), 2006.

8. Nanni A, North American design guidelines for concrete reinforcement and strengthening using FRP: principles, applications and unresolved issues, Proceedings of the International Conference on FRP Composites in Civil Engineering, Edited by J.G. Teng, Hong-Kong (China), vol. 1, 2001, p. 61-72.

9. J. Tomás San-José, Iñigo Vegas, Find Meyer. Structural analysis of FRP reinforced polymer concrete material, Constr. Build. Mater. 2006; 20/971-981.

10. A. Avei, H. Arikan, A Akdemir, Fracture behaviour of glass reinforced polymer composite, Cem. Concr. Res. 2004; 34: 429-434.

11. S.W. Tsui and F.R. Jones, Compos. Sci. Technol., 1992; 44/137-143.

12. J.M.L. Reis, Fracture and flexural characterization of natural fibre-reinforced polymer concrete, Constr. Build. Mater. 2006; 20-10/888-892.

13. Kwan-ho kim et al, The investigation of the equivalent rectangular stress block for highstrength polymer concrete beams, Proceedings of International Congress on Polymers in Concrete (ICPIC'01), Ed. D. Fowler. Hawai (USA), 2001.

14. Mesfer M. Al-Zahrani, Effect of accelerated laboratory conditions on tensile strength and moisture absorption of two types of GFRP bars, Proceedings of 8th International Symposium on Fiber Reinforced Polymer Reinforcement for Concrete Structures (FRPRCS-8), ISBN 978-960-89691-0-0. Editor Prof. T.C. Triantafillou, University of Patras.. (Greece), 2007.

15. Salah U. Al-Dulaijan, Bond behavior of gfrp bars exposed to seawater, sabkha, and thermal variations, Proceedings of Composites in Construction 2005 - Third International Conference. Lyon (France), 2005.

16. J. Tomás San-José, Iñigo Vegas, Antonio Ferreira, Reinforced polymer concrete: physical properties of the matrix and static/dynamic bond behaviour, Cem. Concr. Compos. 2005;27:934-944.

17. A. Katz, Bond to concrete FRP bars after cycling loading, J. Compos. Constr. 2000;137.

18. Rebeiz, K.S.; Fowler, D.W.: Flexure for reinforced polymer concrete using recycled pet. ICPIC'01 Hawai (USA). 2001.

19. San-José, JT. Highly durable precasted special concrete reinforced with non-metallic rebars Plasticrete, European Project contract BRPR-CT98-0708, Bilbao, Fundación Labein, 2002.

20. Kaeding, A.O. Predicting the in-service performance of precast reinforced polymer concrete. 43rd Annual Conference, Composites Institute, The Society of the Plastics Industry, Inc. February, 1-5, 1998.

21. Abdel-Fattah, H. and El-Hawary, M.M. "Flexural Behaviour of Polymer Concrete". Construction and Building Materials 13 (1999) p.p. 253-262. 